\title{
Water vapour profiles from Raman lidar automatically calibrated by microwave radiometer data during HOPE
}

\author{
A. Foth ${ }^{1}$, H. Baars ${ }^{2}$, P. Di Girolamo ${ }^{3}$, and B. Pospichal ${ }^{1}$ \\ ${ }^{1}$ Leipzig Institute for Meteorology, University of Leipzig, Leipzig, Germany \\ ${ }^{2}$ Leibniz Institute for Tropospheric Research, Leipzig, Germany \\ ${ }^{3}$ Scuola di Ingegneria, Università degli Studi della Basilicata, Potenza, Italy \\ Correspondence to: A. Foth (andreas.foth@uni-leipzig.de)
}

Received: 8 December 2014 - Published in Atmos. Chem. Phys. Discuss.: 5 March 2015

Revised: 11 June 2015 - Accepted: 15 June 2015 - Published: 16 July 2015

\begin{abstract}
In this paper, we present a method to derive water vapour profiles from Raman lidar measurements calibrated by the integrated water vapour (IWV) from a collocated microwave radiometer during the intense observation campaign HOPE in the frame of the $\mathrm{HD}(\mathrm{CP})^{2}$ initiative. The simultaneous observation of a microwave radiometer and a Raman lidar allowed an operational and continuous measurement of water vapour profiles also during cloudy conditions. The calibration method provides results which are in a good agreement with conventional methods based on radiosondes. The calibration factor derived from the proposed IWV method is very stable with a relative uncertainty of $5 \%$. This stability allows for the calibration of the lidar even in the presence of clouds using the calibration factor determined during the most recent clear sky interval. Based on the application of this approach, it is possible to retrieve water vapour profiles during all non-precipitating conditions. A statistical analysis shows a good agreement between the lidar measurements and collocated radiosondes. The relative biases amount to less than $6.7 \%$ below $2 \mathrm{~km}$.
\end{abstract}

\section{Introduction}

Water vapour plays a key role in the description of the thermodynamic state of the atmosphere (Hartmann et al., 2013) and it is the most important greenhouse gas (Twomey, 1991). Its amount in the atmosphere is controlled mostly by the air temperature rather than by emissions (Myhre et al., 2013). Therefore, tropospheric water vapour is considered a feedback agent more than a forcing to climate change. Due to its spatio-temporal variability and its involvement in many atmospheric processes (e.g. cloud formation), it is difficult to properly implement water vapour in climate models (Held and Soden, 2000; Tompkins, 2002). Uncertainties in both observations and modelling of water vapour strongly affect the representation of clouds and precipitation in climate models and predictions. For that reason the German research project High Definition Clouds and Precipitation for advancing Climate Prediction $\left(\mathrm{HD}(\mathrm{CP})^{2}\right)$ was initiated aiming to improve the clouds and precipitation representation in models and to quantify the errors associated. One part within the $\mathrm{HD}(\mathrm{CP})^{2}$ initiative was the intense observation campaign $\mathrm{HD}(\mathrm{CP})^{2}$ Observational Prototype Experiment (HOPE) in Jülich. During HOPE different remote-sensing instruments to measure water vapour, both active and passive, were deployed. An active method is given by the Raman lidar technique (Ansmann et al., 1992; Whiteman et al., 1992; Wandinger, 2005). Raman lidars enable high vertical resolution measurements of water vapour and were therefore applied in several field studies such as IHOP (Weckwerth et al., 2004; Whiteman et al., 2006b) or COPS (Herold et al., 2011; Wulfmeyer et al., 2011; Bhawar et al., 2011). However, Raman lidars provide no water vapour information from inside the cloud or above (for optically thick clouds) so that lidar measurements are limited from the surface to the cloud base. Furthermore, daytime measurements are limited in height due to the presence of scattered solar radiation. In addition, water vapour Raman lidars need to be calibrated with an instrument measuring simultaneously for example a microwave radiometer (MWR) or radiosonde (RS) (Madonna et al., 2011; Mattis et al., 2002). Passive microwave radiometry provides atmo- 
spheric water vapour observations with high temporal resolution, but limited vertical information (Westwater et al., 2005). However, the integrated water vapour (IWV) can be retrieved very accurately. In addition, microwave radiometers can be operated during all weather conditions except for precipitation.

In contrast to the already presented remote-sensing observations water, vapour profiles can be measured in situ using radiosondes. RS launches are mostly performed by the national weather services and usually twice a day. Therefore, the horizontal and temporal resolution of routine measurements is rather low.

As described above it is a challenge to provide continuous high-resolution water vapour profiles with a single instrument. In recent years several supersites, like the Jülich Observatory for Cloud Evolution (JOYCE), the Leipzig Aerosol and Cloud Remote Observations System (LACROS) and the Richard Assmann Observatory (RAO), installed a combination of remote-sensing systems. The synergy of these instruments provides complementary information on the water vapour structure. Thus, when both Raman lidar and MWR are measuring collocated and simultaneously at supersites, continuous water vapour profiles can be obtained operationally (Ferrare et al., 2006; Adam and Venable, 2007; Adam et al., 2010). The major objective of this paper is to apply a Raman lidar calibration method which is only based on IWV from MWR in a very straightforward way to offer a broad application. In previous approaches the total precipitable water from MWR in combination with RS has been used to calibrate the water vapour Raman lidar (Turner and Goldsmith, 1999; Turner et al., 2002). We demonstrate that the lidar calibration with MWR is as accurate as conventional methods based on RS allowing operational applicability.

Using the presented calibration method water vapour profiles can be retrieved from ground up to cloud base. In future studies these operationally generated water vapour profiles will serve as input into an optimal estimation technique to retrieve water vapour from within or above the cloud. Therefore, we will develop a two-step algorithm combining Raman lidar mass mixing ratio and MWR brightness temperatures. Both steps, the Kalman filter and the one dimensionalvariational retrieval method will improve the accuracy of the water vapour measurement and will provide reliable data under most conditions except during rainy periods.

\section{Instrumentation}

In the framework of the $\mathrm{HD}(\mathrm{CP})^{2}$ initiative HOPE was conducted around Jülich in western Germany during April and May 2013 (Macke, 2014). The goal of HOPE was to probe the atmosphere with a specific focus on the development of clouds and precipitation. HOPE was further conceived for a critical model evaluation and to provide information on sub-grid variability and microphysical properties. Two ob- servatories were set up in addition to JOYCE. The LACROS site was temporarily built up in Krauthausen which is about $4 \mathrm{~km}$ south of JOYCE. Both JOYCE and LACROS observatories are equipped with a set of active and passive remotesensing instruments such as lidars and MWRs. Radiosondes were launched in Hambach which is about $4 \mathrm{~km}$ away from JOYCE and LACROS (Fig. 1). In the following subsections we present the instruments used for this study.

\subsection{Lidars}

\subsubsection{Polly ${ }^{X T}$}

The lidar measurements at the LACROS site were conducted with the fully automatic portable multiwavelength Raman and polarization lidar Polly ${ }^{\mathrm{XT}}$ (Althausen et al., 2009) by the Leibniz Institute for Tropospheric Research (TROPOS). Polly ${ }^{\mathrm{XT}}$ measures backscattered light at wavelengths of 355 , 532 and $1064 \mathrm{~nm}$ and Raman scattered light at 387, 407 and $607 \mathrm{~nm}$ wavelengths. From that, water vapour profiles can be retrieved (see Sect. 3). In the lowermost heights the overlap of the laser beam with the receiver field-of-view of the bistatic system is incomplete. However, the overlap of both Raman channels is assumed to be identical and for that reason the overlap effect is negligible when regarding water vapour measurements. During daytime, no water vapour measurements can be performed due to the high daylight background. The vertical and temporal resolution of the raw data is $30 \mathrm{~m}$ in height and $30 \mathrm{~s}$ in time. The smoothing lengths amount to $90 \mathrm{~m}$ and $90 \mathrm{~s}$.

\subsubsection{BASIL}

During the HOPE campaign the University of Basilicata lidar system (BASIL) was deployed at the JOYCE site. BASIL has been developed by the Engineering School (formerly the Department of Environmental Engineering and Physics) of the University of Basilicata in Potenza. BASIL performs high resolution and accurate measurements of atmospheric water vapour, both during daytime and nighttime. A thorough description of the technical characteristics, measurement capabilities and performances is given in Di Girolamo et al. (2009). For water vapour measurements BASIL uses the same wavelengths as Polly ${ }^{\mathrm{XT}}$. The maximum vertical and temporal resolution are $7.5 \mathrm{~m}$ in height and $1 \mathrm{~s}$ in time, respectively, and can be traded-off to improve the measurement precision. The time resolution used in this study amounts to $1 \mathrm{~min}$ and $7.5 \mathrm{~s}$. In contrast to Polly ${ }^{\mathrm{XT}}$, the more powerful laser of BASIL enables measurements also during daytime. Due to the use of a non-paralyzable counting system and the high count rate of the BASIL measurements, a dead time correction is applied. For an automatic analysis of the BASIL data only the digital signals are used. For that reason a dry bias in the lowermost $500 \mathrm{~m}$ is expected. The accuracy of the profiles could be improved by gluing the analogue and 


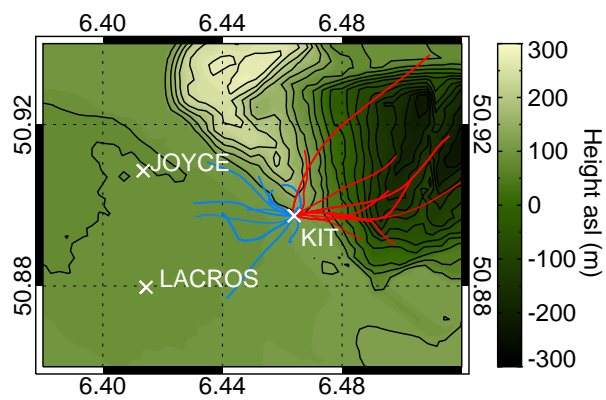

Figure 1. Map of the area around Jülich with westward (blue) and eastward (red) RS trajectories. The darker area in the east indicates the open-cast mining and the brighter area in the north indicates a hill named Sophienhöhe.

the digital signals (Whiteman et al., 2006a; Newsom et al., 2009), but this approach is not considered in this work, which is only focused on demonstrating the automated calibration procedure. This is to simplify the data analysis procedure and to allow for an easier implementation of the automated calibration procedure.

\subsection{Microwave radiometer HATPRO}

The humidity and temperature profiler (HATPRO) is a passive instrument that measures atmospheric emission at two frequency bands in the microwave spectrum. Seven chan-

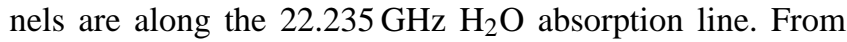
these observations humidity information can be retrieved. The seven channels of the other band from 51 to $58 \mathrm{GHz}$ along the $\mathrm{O}_{2}$ absorption complex contain the vertical temperature profile information. The fully automatic microwave radiometer HATPRO allows to derive temperature and humidity profiles as well as integrated quantities such as IWV and liquid water path (LWP) with a high temporal resolution up to $1 \mathrm{~s}$ (Rose et al., 2005). Observations are possible during nearly all weather conditions except precipitation.

To retrieve atmospheric quantities from the measured brightness temperatures, statistical algorithms were used by means of a multi-linear regression between modelled brightness temperatures and atmospheric profiles. Both MWRs from JOYCE and LACROS use the same retrieval algorithms which are based on a long-term data set of De Bilt radiosondes (Löhnert and Crewell, 2003). The accuracy of the temperature information in the planetary boundary layer can be enhanced through measurements at different elevation angles (Crewell and Löhnert, 2007). The scan mode requires horizontally homogeneous atmospheric conditions in the direct horizontal vicinity $(\sim 3 \mathrm{~km})$.

\subsection{Radiosonde}

Radiosondes (RS) were launched minimum twice a day (11:00 and 23:00 UTC) and more often during intensive observation periods (IOP) at the KITCube site in Hambach.
The RS (type Graw DFM-09) measures temperature, humidity, pressure and wind velocity (Nash et al., 2011). Due to the vicinity of the RS station to the open-cast mining and its depth of nearly $400 \mathrm{~m}$, horizontal inhomogeneities between the RS and the lidar locations are likely (Fig. 1).

\section{Methodology}

The Raman lidar technique enables the determination of water vapour mixing ratio profiles using the inelastic backscatter from nitrogen at $387 \mathrm{~nm}$ and from water vapour at $407 \mathrm{~nm}$ (Whiteman, 2003; Wandinger, 2005). The Raman lidar equation for inelastic signals can be written as

$$
\begin{aligned}
P_{\lambda_{\mathrm{R}}}(z) & =\frac{P_{0, \lambda_{0}} K_{\lambda_{\mathrm{R}}} O_{\lambda_{R}}(z)}{z^{2}} \beta_{\lambda_{\mathrm{R}}}(z) \\
& \times \exp \left\{-\int_{0}^{z}\left[\alpha_{\lambda_{0}}(\xi)+\alpha_{\lambda_{\mathrm{R}}}(\xi)\right] \mathrm{d} \xi\right\}
\end{aligned}
$$

and describes the Raman signals $P_{\lambda_{\mathrm{R}}}(z)$ from distance $z$ measured with a lidar at the Raman wavelength $\lambda_{\mathrm{R}} . P_{0, \lambda_{0}}$ is the emitted laser power at $\lambda_{0} . K_{\lambda_{\mathrm{R}}}$ denotes the system constant and combines all the range-independent system parameters. $O_{\lambda_{\mathrm{R}}}(z)$ is the overlap factor. $\beta_{\lambda_{\mathrm{R}}}(z)$ represents the molecular backscatter coefficient as a function of range. The exponential term characterises the extinction of light on the way from the lidar to the backscattering molecule $\left(\alpha_{\lambda_{0}}(z)\right)$ at the emitted wavelength $\lambda_{0}$ and on the way back to the lidar $\left(\alpha_{\lambda_{R}}(z)\right)$ at the Raman wavelength $\lambda_{R}$. One has to consider that the wavelength is shifted after the Raman scattering process.

The Raman backscatter coefficient

$\beta_{\lambda_{\mathrm{R}}}(z)=N_{\lambda_{\mathrm{R}}}(z) \frac{\mathrm{d} \sigma_{\lambda_{\mathrm{R}}}(\pi)}{\mathrm{d} \Omega}$,

is given by the molecule number density $N_{\lambda_{\mathrm{R}}}(z)$ of the Raman-active gas and the differential cross section for the backward direction $\mathrm{d} \sigma_{\lambda_{R}}(\pi) / \mathrm{d} \Omega$.

The mixing-ratio of water vapour to dry air $m_{\mathrm{H}_{2} \mathrm{O}}$ is defined as:

$m_{\mathrm{H}_{2} \mathrm{O}}=\frac{\rho_{\mathrm{H}_{2} \mathrm{O}}(z)}{\rho_{\text {air }}(z)} \sim \frac{N_{\mathrm{H}_{2} \mathrm{O}}(z)}{N_{\mathrm{N}_{2}}(z)}$,

with $\rho_{\mathrm{H}_{2} \mathrm{O}}$ and $\rho_{\text {air }}$ as density of water vapour and dry air, respectively. $m_{\mathrm{H}_{2} \mathrm{O}}$ is also proportional to the ratio of the molecular number densities of water vapour and nitrogen. Inserting Eqs. (1) and (2) in Eq. (3) $m_{\mathrm{H}_{2} \mathrm{O}}$ is determined by:

$m_{\mathrm{H}_{2} \mathrm{O}}=C_{\mathrm{H}_{2} \mathrm{O}} \frac{P_{\mathrm{H}_{2} \mathrm{O}}(z)}{P_{\mathrm{N}_{2}}(z)} \frac{\exp \left[-\int_{0}^{z} \alpha_{\lambda_{\mathrm{N}_{2}}}(\xi) \mathrm{d}(\xi)\right]}{\exp \left[-\int_{0}^{z} \alpha_{\lambda_{\mathrm{H}_{2} \mathrm{O}}}(\xi) \mathrm{d}(\xi)\right]}$.

In Eq. (4) identical overlap factors were assumed. Differences in the range-independent Raman backscatter cross sections for both channels are absorbed within the calibration 
factor $C_{\mathrm{H}_{2} \mathrm{O}}$ whereon we focus in this paper. The second term indicates the signal ratio which is directly measured. The third term describes the difference between the atmospheric transmission at $\lambda_{\mathrm{N}_{2}}$ and $\lambda_{\mathrm{H}_{2} \mathrm{O}}$. The extinction coefficients $\alpha_{\lambda_{\mathrm{N}_{2}}}(z)$ and $\alpha_{\lambda_{\mathrm{H}_{2} \mathrm{O}}}(z)$ consist of a molecular (superscript $\mathrm{m}$ ) and a particle part (superscript $\mathrm{p}$ ). Figure 2a and $b$ displays the vertical profiles of the molecular and particle extinction coefficients for both Raman channels on 5 May 2013, 23:10 UTC measured with Polly ${ }^{\mathrm{XT}} . \alpha_{\lambda_{\mathrm{N}_{2}}}^{\mathrm{m}}(z)$ and $\alpha_{\lambda_{\mathrm{H}_{2} \mathrm{O}}}^{\mathrm{m}}(z)$ are calculated by using temperature profiles from the MWR and standard atmosphere pressure profiles $(\mathrm{Bu}-$ choltz, 1995). $\alpha_{\lambda_{\mathrm{N}_{2}}}^{\mathrm{p}}(z)$ and $\alpha_{\lambda_{\mathrm{H}_{2} \mathrm{O}}}^{\mathrm{p}}(z)$ can be determined by the Raman method using the particle extinction coefficient at $355 \mathrm{~nm}$ and a certain Ångström-exponent, but they are strongly influenced by the overlap effect. In contrast, the particle backscatter coefficient from the Raman method is the ratio between the elastic signal at $355 \mathrm{~nm}$ and the inelastic signal at $387 \mathrm{~nm}$ and is therefore not affected by the overlap (Ansmann et al., 1992). Hence, the particle extinction coefficients are calculated from the particle backscatter coefficients multiplied by a certain height-independent lidar ratio (i.e. extinction-to-backscatter ratio) of $50 \mathrm{sr}$ (Müller et al., 2007) over the full height range. The particle extinction coefficients are strongly smoothed, therefore there is no strong decrease in the lowermost layers. For the calculation of the particle backscatter coefficient at the Raman wavelengths, a spectral dependence with a backscatter-related Ångströmexponent of 1 is assumed. The determined aerosol optical depth (AOD) at $355 \mathrm{~nm}$ amounts to 0.22 on 5 May 2013, 23:10 UTC.

The resulting differential transmission ratios are illustrated in Fig. 2c. The black line indicates the influence by the differences in the atmospheric transmission at both Raman wavelengths. With a longer path through the atmosphere the influence of the differential transmission increases. By completely neglecting the differences in the atmospheric transmission, the error is less than $2.9 \%$ below $2 \mathrm{~km}$ where most of the water vapour is located. In $10 \mathrm{~km}$ the value is $6.8 \%$ but in this altitude the amount of water vapour is rather low. Since it is quite an effort to retrieve aerosol extinction profiles operationally, we neglect the particle contribution to the transmission. The resulting error amounts to $1.3 \%$ at $2 \mathrm{~km}$ (blue line). These values are in a good agreement with studies on a modelled atmosphere (Whiteman, 2003).

The temperature dependence of the water vapour Raman spectrum portion that is selected by the interference filter is not considered in this paper. For the optical setup of both lidars used here, the effect is negligible in the lower troposphere according to Whiteman (2003).

For Polly ${ }^{\mathrm{XT}}$ and BASIL the lowermost 400 and $100 \mathrm{~m}$, respectively, of the signal ratio are assumed to be well mixed and are set constant to account for the overlap problem. The associated errors amount to a maximum of 0.6 and $0.1 \mathrm{~g} \mathrm{~kg}^{-1}$ at the surface for Polly ${ }^{\mathrm{XT}}$ and BASIL, respectively. These

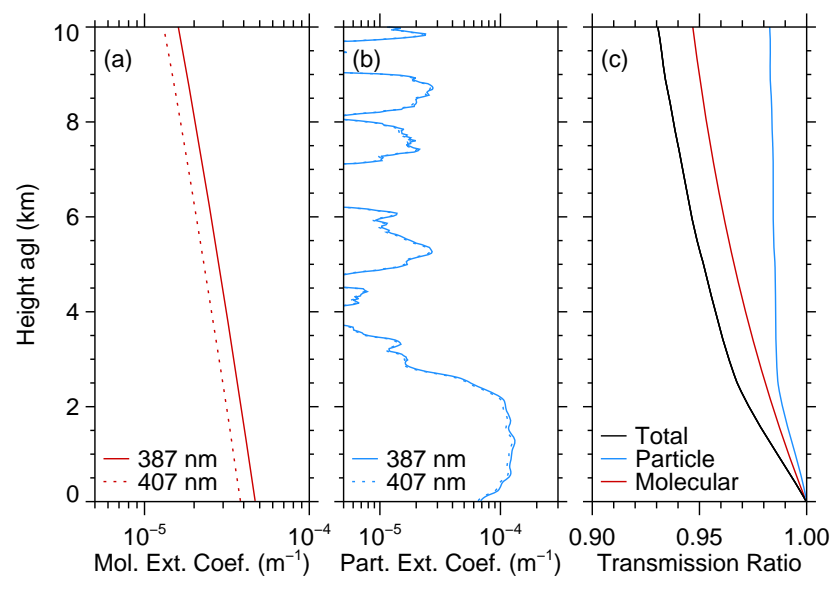

Figure 2. (a) Calculated profiles of the molecular extinction coefficient at 387 and $407 \mathrm{~nm}$. (b) Determined particle extinction coefficient at 387 and $407 \mathrm{~nm}$ from a Polly XT measurement on 5 May 2013, 23:10 UTC. (c) Resulting transmission ratio considering the molecular (red), the particle (blue) contribution and the the sum of both (black).

errors are estimated using the average over nighttime radiosonde profiles during HOPE.

\subsection{Calibration methods}

After considering the uncertainties explained above, the calibration factor $C_{\mathrm{H}_{2} \mathrm{O}}$ can be determined by comparison with simultaneous measurements from a reference instrument. In the following subsections three different methods with two instruments (MWR and RS) are presented in detail for a clear sky night from a Polly ${ }^{\mathrm{XT}}$ measurement on 5 May 2013 (HOPE IOP 12). Afterwards, the stability of the IWV method during the 2 month period of HOPE is presented.

\subsubsection{Regression method}

The regression method can be used to calibrate the lidar profile with an RS (England et al., 1992) by performing a linear regression between the water vapour mixing ratio from the $\mathrm{RS}$ and the signal ratio $P_{\mathrm{H}_{2} \mathrm{O}} / P_{\mathrm{N}_{2}}$ from the lidar (see Fig. 3a). The calibration factor $C_{\mathrm{H}_{2} \mathrm{O}}$ is defined as the slope of the regression line. In our case, the calibration factor amounts to $12.32 \mathrm{~g} \mathrm{~kg}^{-1}$. The standard error of the slope $\left(\sigma C_{\mathrm{H}_{2} \mathrm{O}}\right)$ is $0.17 \mathrm{~g} \mathrm{~kg}^{-1}$ and the correlation coefficient $R^{2}=0.98$ shows a good correlation between the lidar signal and the mixing ratio from the RS. This results in a relative error of $1.4 \%$. The signal ratio is corrected for differential transmission and is averaged over $20 \mathrm{~min}$ from 23:00 to 23:20 UTC. The vertical smoothing amounts to $270 \mathrm{~m}$. Only an altitude region from 2 up to $5 \mathrm{~km}$ is regarded for the regression to exclude boundary layer inhomogeneities in the water vapour structure and to avoid differences due to the RS drift in higher altitudes. 

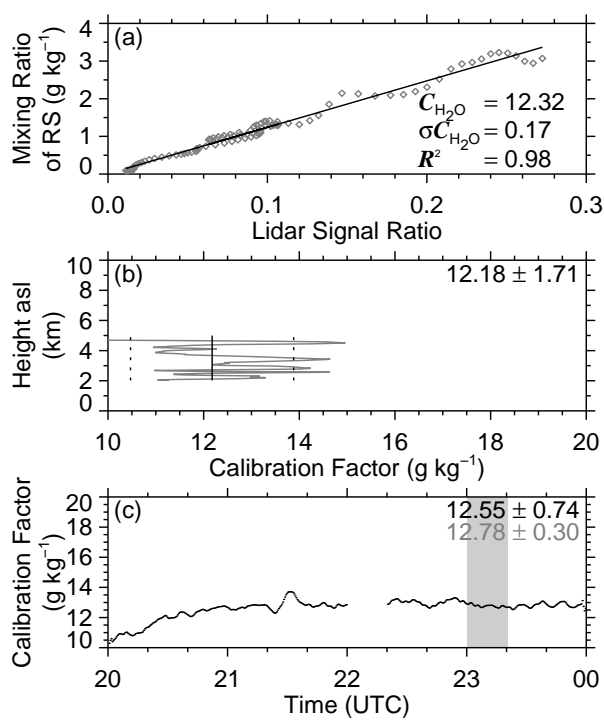

Figure 3. Calibration methods for a clear sky night from a Polly XT measurement on 5 May 2013 (HOPE IOP 12): (a) regression method. Water vapour mixing ratio of the radiosonde (RS) as function of the signal ratio from the lidar averaged over $20 \mathrm{~min}$ from 23:00 to 23:20 UTC. $C_{\mathrm{H}_{2} \mathrm{O}}$ is the slope of the regression line, $\sigma C_{\mathrm{H}_{2} \mathrm{O}}$ is the standard error of the slope and $R^{2}$ is the coefficient of determination. (b) Profile method. The calibration factor for each considered height bin. The numbers indicate the mean calibration factor and its standard deviation. (c) IWV method. Time series of the calculated calibration factor (black line). The black numbers denote the mean and the standard deviation of the whole time range, whereas the grey numbers correspond to the time range of the RS ascent (grey area).

Using this method, Dionisi et al. (2010) found a variability in the calibration factor of about $10 \%$.

\subsubsection{Profile method}

Another method to calibrate the lidar with an RS is the profile method with an associated uncertainty of about $5 \%$ (Mattis et al., 2002; Reichardt et al., 2012). $C_{\mathrm{H}_{2} \mathrm{O}}$ is calculated by the temporal mean of the water vapour mixing ratio measured with RS and the signal ratio from the lidar for each considered height bin. This ratio varies with altitude resulting in a mean calibration factor of $12.18 \mathrm{~g} \mathrm{~kg}^{-1}$ and a standard deviation of $1.71 \mathrm{~g} \mathrm{~kg}^{-1}$ (Fig. 3b). The relative error amounts to $14 \%$. Here, the same time range, altitude region and vertical smoothing as for the regression method are applied.

\subsubsection{IWV method}

In previous experiments (Ferrare et al., 1995; Herold et al., 2011), radiosondes showed a significant sonde-to-sonde variability (Nash et al., 2006) as well as a dry bias (Turner et al., 2003). For that reason, water vapour Raman lidars were often calibrated based on the IWV or integrated precipitable

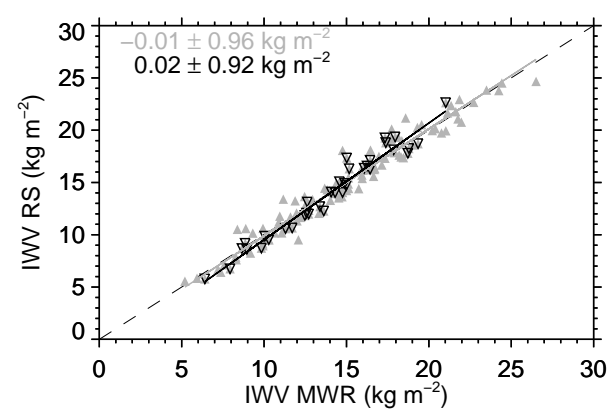

Figure 4. Comparison between IWV from MWR and RS during HOPE. Grey and black triangles indicate all weather conditions and only clear sky conditions, respectively. The solid lines notify the according regression lines. The numbers in the upper left corners denote the bias and the standard deviation, respectively.

water retrieved from a MWR resulting in a relative uncertainty of $5 \%$ (Turner and Goldsmith, 1999), $7 \%$ (Madonna et al., 2011) and $3 \%$ (Adam et al., 2010), respectively.

Before using the MWR for the calibration of the lidar it is necessary to estimate the accuracy of the IWV. Figure 4 displays the IWV comparison between MWR and RS. On average the bias during all weather conditions and clear sky is very low with values of $-0.01 \pm 0.96$ and $0.02 \pm$ $0.92 \mathrm{~kg} \mathrm{~m}^{-2}$ (mean $\pm \mathrm{SD}$ ), respectively. However, during drier (IWV $<7 \mathrm{~kg} \mathrm{~m}^{-2}$ ) or more humid (IWV $>20 \mathrm{~kg} \mathrm{~m}^{-2}$ ) clear sky conditions the relative difference can amount to $10 \%$. These relative differences have to be considered when calibrating lidar profiles.

Using the IWV method, $C_{\mathrm{H}_{2} \mathrm{O}}$ is defined as the ratio of the IWV measured with the MWR and the integrated signal ratio from the lidar. For simultaneous measurements from MWR and lidar, $C_{\mathrm{H}_{2} \mathrm{O}}$ can be calculated from the mean of its time series during clear sky. To determine clear sky periods, two criteria have to be fulfilled. First, the standard deviation of LWP from MWR within a 20 min interval should amount to less than a threshold of $1.5 \mathrm{~g} \mathrm{~m}^{-2}$. The second one is based on the detection of a potential cloud base with the lidar signal at $1064 \mathrm{~nm}$. Profiles with cloud bases higher than $6 \mathrm{~km}$ are treated as clear sky profiles. For that reason, the integrated signal ratio of the lidar is calculated by integrating the profiles from the ground to $6 \mathrm{~km}$. Water vapour above this height is mostly negligible. In that way, the lidar can be calibrated in the presence of high clouds.

The time series of the calculated $C_{\mathrm{H}_{2} \mathrm{O}}$ is presented in Fig. 3c. The mean and the standard deviation are 12.77 and $0.36 \mathrm{~g} \mathrm{~kg}^{-1}$, respectively. Regarding only the time range which is used for the calibration with the RS, the mean amounts to $12.78 \mathrm{~g} \mathrm{~kg}^{-1}$ and the standard deviation to $0.3 \mathrm{~g} \mathrm{~kg}^{-1}$. The relative error thus does not exceed $3 \%$.

To give an overview, the calibration factors and errors of all presented methods are summarized in Table 1 . The relative difference between these methods amounts to less than 
Table 1. Calibration factors and errors of the regression, profile and IWV method.

\begin{tabular}{lrr}
\hline Method & $C_{\mathrm{H}_{2} \mathrm{O}}\left(\mathrm{g} \mathrm{kg}^{-1}\right)$ & $\sigma C_{\mathrm{H}_{2} \mathrm{O}}\left(\mathrm{g} \mathrm{kg}^{-1}\right)$ \\
\hline Regression & 12.32 & 0.17 \\
Profile & 12.18 & 1.71 \\
IWV & 12.78 & 0.3 \\
\hline
\end{tabular}

$5 \%$. The IWV method is well suited to avoid errors due to the RS drift.

\subsection{Stability of the calibration factor}

Having demonstrated that the calibration factors of all three methods are in a good agreement, we will here discuss the stability of the IWV method. Figure 5 presents the time series of the calibration factor of Polly ${ }^{\mathrm{XT}}$ using the IWV method (black and blue lines). The grey areas denote the standard deviation during each $20 \mathrm{~min}$ interval. Rearrangements in the optical setup of Polly ${ }^{\mathrm{XT}}$, more specifically adjustments of the overlap or cleanups of the quartz plate in the roof of the Polly ${ }^{\mathrm{XT}}$ cabinet can cause changes in the calibration factor. Such rearrangements or time leaps of more than $4 \mathrm{~h}$ are indicated by dotted lines. The means and standard deviations amount to $15.2 \pm 0.4$ and $12.4 \pm 0.6 \mathrm{~g} \mathrm{~kg}^{-1}$ before and after the major rearrangement in the optical setup on 15 April 2013, 10:06 UTC, respectively. These values correspond to relative errors of 3 and $5 \%$ and are comparable to studies of Mona et al. (2007) and Sakai et al. (2007). Without any strong rearrangements in the optical setup, the calibration factor is very stable, enabling an operational applicability. This is particularly important during cloudy conditions when no calibration can be performed. In those cases, the calibration factor from the last 20 min clear sky interval can be applied. This is explained in more detail in Sect. 4.4.

Furthermore, the calibration factors determined by the regression method (red points and error bars) and the profile method (green plus signs) are added to Fig. 5. Their uncertainties amount to $11.9 \pm 1.3 \mathrm{~g} \mathrm{~kg}^{-1}(11 \%)$ and $13.3 \pm$ $1.3 \mathrm{~g} \mathrm{~kg}^{-1}(10 \%)$, respectively. The error bars of the profile method are too large and are omitted for clarity.

\section{Water vapour measurements}

The availability of two Raman lidar systems as well as frequent RS launches allow a statistical analysis of the water vapour profile accuracy. This section starts with an overview over the Polly ${ }^{\mathrm{XT}}$ water vapour observation during HOPE. Afterwards, a case study comparing water vapour measurements of Polly ${ }^{\mathrm{XT}}$, BASIL and RS is presented. This part is followed by an extensive statistical analysis showing the accuracy of the IWV method for the whole experimental pe-

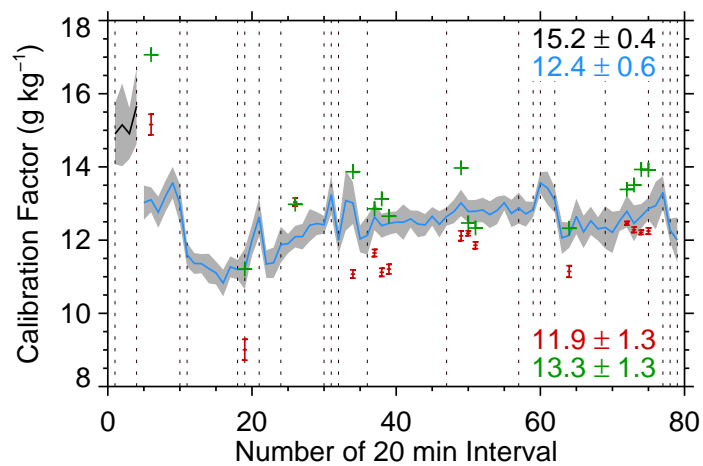

Figure 5. Calibration factor of Polly ${ }^{X T}$ using the IWV method as function of time given in number of 20 min interval. The black and the blue solid lines indicate the calibration factor before and after the major rearrangement of the optical setup on 15 April 2013, 10:06 UTC, respectively. The grey areas denote the standard deviation during each $20 \mathrm{~min}$ interval. The numbers represent the according means and standard deviations over the time. The grey dotted lines demonstrate rearrangements on Polly $\mathrm{XT}$ especially adjustments of the overlap or cleanups of the quartz plate in the roof of the Polly ${ }^{X T}$ cabinet or they indicate leaps in the time of more than $4 \mathrm{~h}$. The calibration factors of the regression and the profile method are indicated by red points with error bars and green plus signs, respectively.

riody. Finally, this section ends with an example of a water vapour measurement in the presence of clouds.

\subsection{Overview over Polly ${ }^{\mathrm{XT}}$ water vapour observations during HOPE}

Using the IWV method, it was possible to obtain calibrated water vapour profiles by Polly ${ }^{\mathrm{XT}}$ during almost every night from 4 April to 29 May 2013 (Fig. 6). The water vapour content in the planetary boundary layer (PBL) is quite variable ranging from about $3 \mathrm{~g} \mathrm{~kg}^{-1}$ on 7 April up to about $8 \mathrm{~g} \mathrm{~kg}^{-1}$ on 8 May 2013. The PBL contains more water vapour than the layers above. However, the water vapour in the top layers was often not observed due to the presence of clouds (e.g. the night from 11 to 12 April 2013). A method to derive water vapour also in cloudy cases is presented in Sect. 4.4.

\subsection{Comparison of water vapour measurements on 4 May 2013}

During the night of 4 to 5 May 2013, clear sky conditions were present over the area and all measurement systems were running. Figure 7a shows a comparison of water vapour mixing ratio profiles from Polly ${ }^{\mathrm{XT}}$, BASIL and RS at 23:00 UTC. The lidar profiles are averaged over $20 \mathrm{~min}$ starting at 23:00 UTC. The vertical smoothing lengths are 90 and $22.5 \mathrm{~m}$ for Polly ${ }^{\mathrm{XT}}$ and BASIL, respectively. Due to the different vertical resolution, the lidar profiles are interpolated to the RS height grid. All three curves show a similar behavior, except within the PBL up to $1.6 \mathrm{~km}$. Above the 


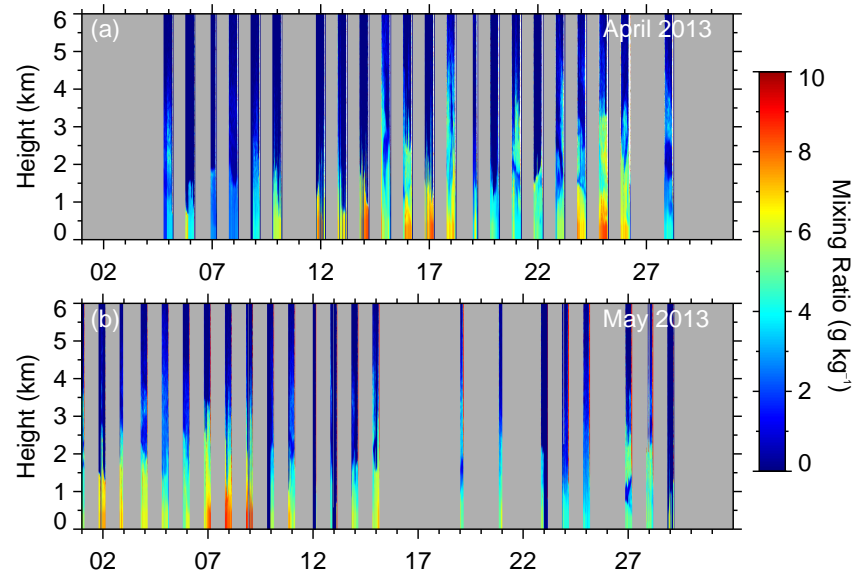

Figure 6. Overview over the water vapour profiles observed by Polly ${ }^{X T}$ during HOPE: (a) April and (b) May 2013.

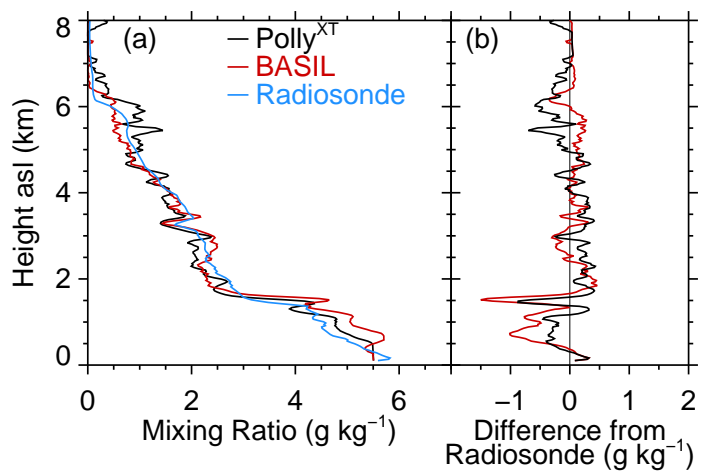

Figure 7. (a) Comparison of the mixing ratio profiles from Polly $\mathrm{XT}$ (black), BASIL (red) and radiosonde (blue) on 5 May 2013, 23:00 UTC. The lidar profiles are averaged over $20 \mathrm{~min}$. (b) Differences in mixing ratio between radiosonde and Polly $\mathrm{XT}$ or BASIL, respectively.

PBL top a strong decrease in the water vapour mixing ratio can be observed. The differences between the RS as independent reference and the lidars are illustrated in Fig. 7b. It can be seen that the discrepancies are quite large in the PBL. The mean difference and its standard deviation in the PBL amount to $-0.14 \pm 0.31 \mathrm{~g} \mathrm{~kg}^{-1}$ (relative error $-3.2 \pm 8.2 \%$ ) and $-0.46 \pm 0.45 \mathrm{~g} \mathrm{~kg}^{-1}(-11.4 \pm 12 \%)$ for Polly ${ }^{\mathrm{XT}}$ (black) and BASIL (red), respectively. These differences are expected due to the normal water vapour variability in the PBL. Negative values indicate drier RS values.

The largest differences occur at the PBL top with $-1 \mathrm{~g} \mathrm{~kg}^{-1}$ (Polly ${ }^{\mathrm{XT}}$ ) and $-1.37 \mathrm{~g} \mathrm{~kg}^{-1}$ (BASIL) which can be caused by small-scale variability of the PBL height. Above the PBL in the free troposphere (FT) between 2 and $5 \mathrm{~km}$ the differences are smaller with values of $0.17 \pm$ $0.17 \mathrm{~g} \mathrm{~kg}^{-1}(8.5 \pm 10.5 \%)$ for Polly ${ }^{\mathrm{XT}}$ and $0.08 \pm 0.17 \mathrm{~g} \mathrm{~kg}^{-1}$ $(4.8 \pm 8.6 \%)$ for BASIL.

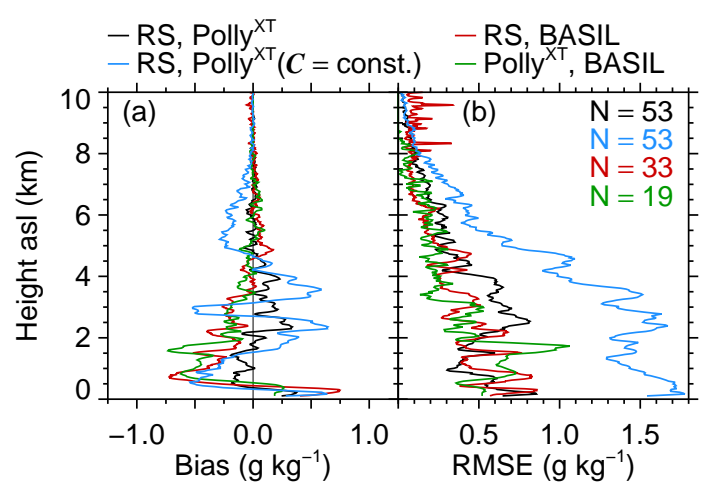

Figure 8. Statistical analysis of lidar profiles determined by the IWV method: (a) Absolute bias between the radiosonde (RS) and Polly ${ }^{X T}$ (black), RS and Polly ${ }^{X T}$ calibrated with a constant calibration factor of 12.4 (blue), between RS and BASIL (red) and between Polly ${ }^{\mathrm{XT}}$ and BASIL (green). (b) Root-mean-square error (RMSE) of the water vapour mixing ratio. The numbers indicate the sample size.

\subsection{Statistical analysis}

For a statistical analysis of the developed calibration method, the absolute bias between RS and Polly ${ }^{\mathrm{XT}}$, as well as between RS and BASIL is presented. For Polly ${ }^{\mathrm{XT}}$ also a constant calibration factor of 12.4 is used, being the average from the IWV method. In the analysis only clear sky nighttime measurements within less than $2 \mathrm{~h}$ before or after the RS launch time are considered. The sample size amounts to 53 and 33 observations, respectively. The profiles are interpolated to the height grid of the lidar and are averaged over $20 \mathrm{~min}$. For the comparison between both lidars only simultaneous $20 \mathrm{~min}$ averages are investigated (19 cases). One has to consider that several lidar profiles were compared to one RS profile (e.g. lidar profiles from 21:20, 21:40 and 22:00 UTC to the RS from 23:00 UTC). The Polly ${ }^{X T}$ and BASIL cases are compared to 15 and 6 radiosondes, respectively.

The absolute bias between RS and Polly ${ }^{\mathrm{XT}}$, as well as the absolute bias between RS and BASIL are largest in the lowermost layer from 0 to $0.5 \mathrm{~km}$ (Fig. 8a). These biases are induced by the different measurement locations and the missing gluing in the BASIL data. This can have an impact on the mixing ratio of up to $1 \mathrm{~g} \mathrm{~kg}^{-1}$ in the lowermost $500 \mathrm{~m}$. In the PBL up to about $2 \mathrm{~km}$, the absolute bias between RS and BASIL and between Polly ${ }^{\mathrm{XT}}$ and BASIL shows negative values indicating that BASIL measures a higher amount of water vapour. These higher biases in the PBL can be explained by the higher variability of water vapour due to the different measurement locations, since the RS launch site (KIT) is directly situated at the open-cast mining.

The trajectories of the RS up to an altitude of $2 \mathrm{~km}$ are shown in Fig. 1 split into the trajectories west and east. Figure 9 depicts the biases between RS and Polly ${ }^{\mathrm{XT}}$ distinguished by the direction of the RS trajectories. When the RS 
Table 2. Absolute and relative bias for water vapour mixing ratio (mean $\pm \mathrm{SD}$ ). Values are represented for the layers from 0 to $2 \mathrm{~km}$, from 2 to $4 \mathrm{~km}$ and from 4 to $10 \mathrm{~km}$.

\begin{tabular}{|c|c|c|c|c|c|c|}
\hline & \multicolumn{2}{|c|}{$0-2 \mathrm{~km}$} & \multicolumn{2}{|c|}{$2-4 \mathrm{~km}$} & \multicolumn{2}{|c|}{$4-10 \mathrm{~km}$} \\
\hline & $\begin{array}{c}\text { Abs. bias } \\
\left(\mathrm{g} \mathrm{kg}^{-1}\right)\end{array}$ & $\begin{array}{r}\text { Rel. bias } \\
(\%)\end{array}$ & $\begin{array}{r}\text { Abs. bias } \\
\left(\mathrm{g} \mathrm{kg}^{-1}\right)\end{array}$ & $\begin{array}{r}\text { Rel. bias } \\
(\%)\end{array}$ & $\begin{array}{l}\text { Abs. bias } \\
\left(\mathrm{g} \mathrm{kg}^{-1}\right)\end{array}$ & $\begin{array}{r}\text { Rel. bias } \\
(\%)\end{array}$ \\
\hline RS-PollyXT & $-0.03 \pm 0.15$ & $-0.6 \pm 2.8$ & $0.14 \pm 0.1$ & $7.5 \pm 5.1$ & $0.01 \pm 0.04$ & $0.6 \pm 15.2$ \\
\hline RS-Polly XT (const) & $-0.09 \pm 0.34$ & $-1.0 \pm 4.8$ & $0.24 \pm 0.36$ & $8.3 \pm 13.8$ & $-0.06 \pm 0.11$ & $-15 \pm .5$ \\
\hline RS-BASIL & $-0.2 \pm 0.4$ & $-5.3 \pm 8.2$ & $-0.15 \pm 0.11$ & $-7.2 \pm 5.1$ & $0.01 \pm 0.04$ & $0.9 \pm 26.5$ \\
\hline Polly ${ }^{X T}$-BASIL & $-0.3 \pm 0.3$ & $-6.7 \pm 6.6$ & $-0.13 \pm 0.08$ & $-7.7 \pm 2.9$ & $-0.02 \pm 0.04$ & $15.4 \pm 148.5$ \\
\hline
\end{tabular}

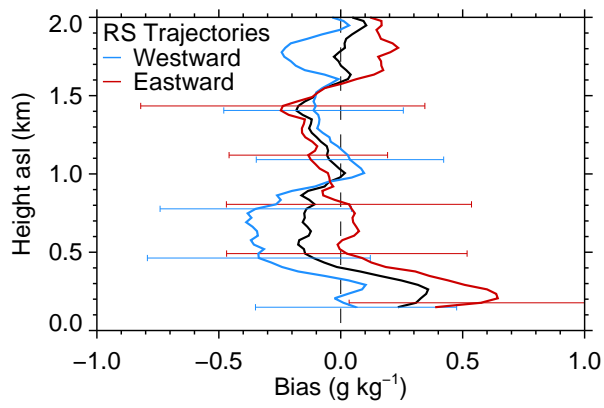

Figure 9. Absolute bias and standard deviation (error bars) between the RS and Polly XT distinguished by different trajectories. The black line indicates the bias considering all trajectories.

drifts to the east (red), the RS rises in an air mass which is not affected by the pit. In these cases, the bias is close to zero at altitudes from 0.5 to $1 \mathrm{~km}$. During the weaker easterly wind conditions, the RS drifts in an air mass which is strongly affected by the pit, whereas the air sounded by the lidar passes the pit southwards and is therefore not disturbed. Here the lidar and the RS do not profile the same air masses resulting in a higher bias down to $-0.4 \mathrm{~g} \mathrm{~kg}^{-1}$. However, the differences between the biases are in the range of their standard deviations.

Above the PBL the biases converge to zero (Fig. 8a). The bias between the RS and Polly ${ }^{\mathrm{XT}}$ shows a small increase at about $2.5 \mathrm{~km}$ caused by four cases in which the atmosphere changes so fast that the lidar and the RS do not measure the same air mass. In high altitudes no significant biases are noticeable. Obviously, the water vapour amount decreases with altitude and therefore the RMSE also decreases with height (Fig. 8b). The coefficient of variation (CV) also known as relative RMSE increases with height due to the decreasing water vapour amount. In high altitudes the $\mathrm{CV}$ is more noisy for all four comparisons.

The bias of the previously described comparisons is summarised in Table 2. It can be seen that the absolute bias is larger in the lower layers up to $4 \mathrm{~km}$ than in the upper layer (4 to $10 \mathrm{~km}$ ). However, large relative biases can occur in the upper layer due to the lower water vapour mixing ratio. In addition, the bias is larger using a constant calibration factor instead of calibration factors determined by the IWV method.

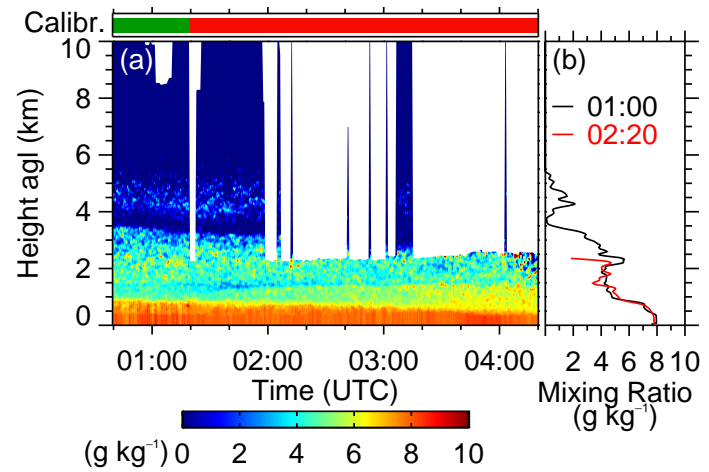

Figure 10. (a) Height-time display of the water vapour mixing ratio from a Polly XT measurement on 16 April 2013, 00:40 UTC. White areas are regions in or above clouds without any water vapour information. The bars on the top indicate which profiles are calibrated (green) based on the current IWV from MWR. The red bars denote profiles which are calibrated with the averaged calibration factor from the last clear sky 20 min interval (red). (b) Profiles of the $20 \mathrm{~min}$ intervals at 01:00 UTC (black) and 02:20 UTC (red).

Brocard et al. (2013) found relative biases within $3 \%$ up to $3 \mathrm{~km}$ during the day, and within 5 to $10 \%$ up to $8 \mathrm{~km}$ during the night. Values of about $0.6 \pm 0.6 \mathrm{~g} \mathrm{~kg}^{-1}$ in the altitude range 1.5 to $5.5 \mathrm{~km}$ were identified by Navas-Guzmán et al. (2014).

\subsection{Water vapour measurements below clouds}

After showing the stability and accuracy of the calibration factor from the IWV method we can calibrate the lidar profiles during all non-precipitating conditions. Figure 10a shows the height-time display of the water vapour mixing ratio from a Polly ${ }^{\mathrm{XT}}$ measurement on 16 April 2013, 00:40 UTC. The white area indicates regions inside or above clouds without any water vapour information. The cloud base was determined by the gradient method on the rangecorrected signal at $1064 \mathrm{~nm}$ (Baars et al., 2008). The green marked profiles until 01:20 UTC are calibrated with the IWV method, whereas the red marked after 01:20 UTC indicate cloudy conditions. These profiles are calibrated using the averaged calibration factor of the last 20 min clear sky interval (01:00 to 01:20 UTC). Both profiles of the water vapour mixing ratio at 01:00 and 02:20 UTC are in a good agree- 
ment below the cloud base (Fig. 10b). With this technique it is possible to provide continuous water vapour profiles up to the cloud base in all non-precipitating night cases.

\section{Conclusions}

In this study, we present water vapour profiles from Raman lidar automatically calibrated by microwave radiometer enabling an operational applicability. It is shown that the calibration factors during HOPE were very stable with a relative error of $5 \%$. This allowed us to retrieve water vapour profiles in all non-precipitating weather conditions. During clear sky cases, the lidar can be calibrated simultaneously with the IWV from the MWR, whereas in cloudy cases the calibration factor from the last 20 min clear sky interval can be applied. Therefore, the lidar setup should only be changed during clear sky conditions.

The presented case study and the statistical analysis show a good agreement between measurements with RS and two different lidar systems calibrated by MWR. This results in rather accurate profiles. The biases between the lidars and the RS can be explained by the different measurement locations and a possible systematic bias in the RS. This could be investigated in further studies.

Particularly with regard to the increasing amount of ground-based remote-sensing supersites that are equipped with Raman lidar and MWR without operational RS launches (e.g. LACROS in Leipzig), water vapour profiles can be retrieved on a routine basis.

Acknowledgements. This work was funded by the Federal Ministry of Education and Research in Germany (BMBF) through the research programme "High Definition Clouds and Precipitation for Climate Prediction - HD(CP) $)^{2}$ (FKZ: 01LK1209D).

The authors acknowledge the BASIL, the LACROS and the radiosonde team for conducting the measurements and like to acknowledge all other supporters of the HOPE campaign.

Edited by: H. Russchenberg

\section{References}

Adam, M. and Venable, D. D.: Systematic distortions in water vapor mixing ratio and aerosol scattering ratio from a Raman lidar, in: SPIE Proceedings, Vol. 6750, Lidar Technologies, Techniques, and Measurements for Atmospheric Remote Sensing III, Florence, Italy, 17-19 September 2007, 67500S, doi:10.1117/12.738205, 2007.

Adam, M., Demoz, B. B., Whiteman, D. N., Venable, D. D., Joseph, E., Gambacorta, A., Wei, J., Shephard, M. W., Miloshevich, L. M., Barnet, C. D., Herman, R. L., Fitzgibbon, J., and Connell, R.: Water Vapor Measurements by Howard University Raman Lidar during the WAVES 2006 Campaign, J. Atmos. Ocean. Tech., 27, 42-60, doi:10.1175/2009JTECHA1331.1, 2010.
Althausen, D., Engelmann, R., Baars, H., Heese, B., Ansmann, A., Müller, D., and Komppula, M.: Portable Raman lidar PollyXT for automated profiling of aerosol backscatter, extinction, and depolarization, J. Atmos. Ocean. Tech., 26, 2366-2378, doi:10.1175/2009JTECHA1304.1, 2009.

Ansmann, A., Wandinger, U., Riebesell, M., Weitkamp, C., and Michaelis, W.: Independent measurement of extinction and backscatter profiles in cirrus clouds by using a combined Raman elastic-backscatter lidar, Appl. Opt., 31, 7113-7131, doi:10.1364/AO.31.007113, 1992.

Baars, H., Ansmann, A., Engelmann, R., and Althausen, D.: Continuous monitoring of the boundary-layer top with lidar, Atmos. Chem. Phys., 8, 7281-7296, doi:10.5194/acp-8-7281-2008, 2008.

Bhawar, R., di Girolamo, P., Summa, D., Flamant, C., Althausen, D., Behrendt, A., Kiemle, C., Bosser, P., Cacciani, M., Champollion, C., di Iorio, T., Engelmann, R., Herold, C., Müller, D., Pal, S., Wirth, M., and Wulfmeyer, V.: The water vapour intercomparison effort in the framework of the Convective and Orographically-induced Precipitation Study: airborne-toground-based and airborne-to-airborne lidar systems, Q. J. R. Meteorol. Soc., 137, 325-348, doi:10.1002/qj.697, 2011.

Brocard, E., Philipona, R., Haefele, A., Romanens, G., Mueller, A., Ruffieux, D., Simeonov, V., and Calpini, B.: Raman Lidar for Meteorological Observations, RALMO - Part 2: Validation of water vapor measurements, Atmos. Meas. Tech., 6, 1347-1358, doi:10.5194/amt-6-1347-2013, 2013.

Bucholtz, A.: Rayleigh-scattering calculations for the terrestrial atmosphere, Appl. Opt., 34, 2765-2773, doi:10.1364/AO.34.002765, 1995.

Crewell, S. and Löhnert, U.: Accuracy of Boundary Layer Temperature Profiles Retrieved With Multifrequency Multiangle Microwave Radiometry., IEEE Trans. Geosci. Remote Sens., 45, 2195-2201, doi:10.1109/TGRS.2006.888434, 2007.

Di Girolamo, P., Summa, D., and Ferretti, R.: Multiparameter Raman lidar measurements for the characterization of a dry stratospheric intrusion event, J. Atmos. Ocean. Tech., 26, 1742-1762, doi:10.1175/2009JTECHA1253.1, 2009.

Dionisi, D., Congeduti, F., Liberti, G. L., and Cardillo, F.: Calibration of a Multichannel Water Vapor Raman Lidar through Noncollocated Operational Soundings: Optimization and Characterization of Accuracy and Variability, J. Atmos. Ocean. Tech., 27, 108-121, doi:10.1175/2009JTECHA1327.1, 2010.

England, M. N., Ferrare, R. A., Melfi, S. H., Whiteman, D. N., and Clark, T. A.: Atmospheric water vapor measurements: Comparison of microwave radiometry and lidar, J. Geophys. Res., 97, 899-916, doi:10.1029/91JD02384, 1992.

Ferrare, R. A., Melfi, S. H., Whiteman, D. N., Evans, K. D., Schmidlin, F. J., and Starr, D. O.: A Comparison of Water Vapor Measurements Made by Raman Lidar and Radiosondes, J. Atmos. Ocean. Tech., 12, 1177-1195, doi:10.1175/15200426(1995)012<1177:ACOWVM>2.0.CO;2, 1995.

Ferrare, R., Turner, D., Clayton, M., Schmid, B., Redemann, J., Covert, D., Elleman, R., Ogren, J., Andrews, E., Goldsmith, J. E. M., and Jonsson, H.: Evaluation of daytime measurements of aerosols and water vapor made by an operational Raman lidar over the Southern Great Plains, J. Geophys. Res. Atmos., 111, D05S08, doi:10.1029/2005JD005836, 2006. 
Hartmann, D., Klein Tank, A., Rusticucci, M., Alexander, L., Brönnimann, S., Charabi, Y., Dentener, F., Dlugokencky, E., Easterling, D., Kaplan, A., Soden, B., Thorne, P., Wild, M., and Zhai, P.: Observations: Atmosphere and Surface, in: Climate Change 2013: The Physical Science Basis. Contribution of Working Group I to the Fifth Assessment Report of the Intergovernmental Panel on Climate Change, edited by: Stocker, T., Qin, D., Plattner, G., Tignor, M., Allen, S., Boschung, J., Nauels, A., Xia, Y., Bex, V., and Midgley, P., Cambridge University Press, Cambridge, United Kingdom and New York, NY, USA, 2013.

Held, I. and Soden, B.: Water vapor Feedback and Global Warming, Annu. Rev. Energy Environ., 25, 441-475, doi:10.1146/annurev.energy.25.1.441, 2000.

Herold, C., Althausen, D., Müller, D., Tesche, M., Seifert, P., Engelmann, R., Flamant, C., Bhawar, R., and di Girolamo, P.: Comparison of Raman Lidar Observations of Water Vapor with COSMODE Forecasts during COPS 2007, Weather Forecast., 26, 10561066, doi:10.1175/2011WAF2222448.1, 2011.

Löhnert, U. and Crewell, S.: Accuracy of cloud liquid water path from ground-based microwave radiometry 1 . Dependency on cloud model statistics, Radio Sci., 38, 8041, doi:10.1029/2002RS002654, 2003.

Macke, A.: HOPE - A German intensive field campaign to capture the spatiotemporal variability of the thermodynamics, energetics, and microphysics of the cloudy troposphere with high resolution, in: 14th Conference on Atmospheric Radiation, J6.4, Boston, MA, USA, 07-11 July 2014.

Madonna, F., Amodeo, A., Boselli, A., Cornacchia, C., Cuomo, V., D’Amico, G., Giunta, A., Mona, L., and Pappalardo, G.: CIAO: the CNR-IMAA advanced observatory for atmospheric research, Atmos. Meas. Tech., 4, 1191-1208, doi:10.5194/amt4-1191-2011, 2011.

Mattis, I., Ansmann, A., Althausen, D., Jaenisch, V., Wandinger, U., Müller, D., Arshinov, Y. F., Bobrovnikov, S. M., and Serikov, I. B.: Relative-humidity profiling in the troposphere with a Raman lidar., Appl. Opt., 41, 6451-6462, doi:10.1364/AO.41.006451, 2002.

Mona, L., Cornacchia, C., D’Amico, G., Di Girolamo, P., Pappalardo, G., Pisani, G., Summa, D., Wang, X., and Cuomo, V.: Characterization of the variability of the humidity and cloud fields as observed from a cluster of ground-based lidar systems, Q. J. R. Meteorol. Soc., 133, 257-271, doi:10.1002/qj.160, 2007.

Müller, D., Ansmann, A., Mattis, I., Tesche, M., Wandinger, U., Althausen, D., and Pisani, G.: Aerosol-type-dependent lidar ratios observed with Raman lidar, J. Geophys. Res., 112, D16202, doi:10.1029/2006JD008292, 2007.

Myhre, G., Shindell, D., Bréon, F.-M., Collins, W., Fuglestvedt, J., Huang, J., Koch, D., Lamarque, J.-F., Lee, D., Mendoza, B., Nakajima, T., Robock, A., Stephens, G., Takemura, T., and Zhang, H.: Anthropogenic and Natural Radiative Forcing, in: Climate Change 2013: The Physical Science Basis. Contribution of Working Group I to the Fifth Assessment Report of the Intergovernmental Panel on Climate Change, edited by: Stocker, T., Qin, D., Plattner, G., Tignor, M., Allen, S., Boschung, J., Nauels, A., Xia, Y., Bex, V., and Midgley, P., Cambridge University Press, Cambridge, United Kingdom and New York, NY, USA, 2013.

Nash, J., Smout, R., Oakley, T., Pathack, B., and Kurnosenko, S.: WMO Intercomparison of Radiosonde Systems, Vacoas, Mauri- tius, 02-25 February 2005, Instruments and observing methods report No. 83, WMO/TD-No. 1303, Geneva, Switzerland, 2006.

Nash, J., Oakley, T., Vömel, H., and Wei, L.: WMO Intercomparison of High Quality Radiosonde Systems, Yangjiang, China, 12 July-03 August 2010, Instruments and observing methods report No. 107, WMO/TD-No. 1580, Geneva, Switzerland, 2011.

Navas-Guzmán, F., Fernández-Gálvez, J., Granados-Muñoz, M. J., Guerrero-Rascado, J. L., Bravo-Aranda, J. A., and AladosArboledas, L.: Tropospheric water vapour and relative humidity profiles from lidar and microwave radiometry, Atmos. Meas. Tech., 7, 1201-1211, doi:10.5194/amt-7-1201-2014, 2014.

Newsom, R. K., Turner, D. D., Mielke, B., Clayton, M., Ferrare, R., and Sivaraman, C.: Simultaneous analog and photon counting detection for Raman lidar, Appl. Opt., 48, 3903-3914, doi:10.1364/AO.48.003903, 2009.

Reichardt, J., Wandinger, U., Klein, V., Mattis, I., Hilber, B., and Begbie, R.: RAMSES: German Meteorological Service autonomous Raman lidar for water vapor, temperature, aerosol, and cloud measurements., Appl. Opt., 51, 8111-8131, doi:10.1364/AO.51.008111, 2012.

Rose, T., Crewell, S., Löhnert, U., and Simmer, C.: A network suitable microwave radiometer for operational monitoring of the cloudy atmosphere, Atmos. Res., 75, 183-200, doi:10.1016/j.atmosres.2004.12.005, 2005.

Sakai, T., Nagai, T., Nakazato, M., Matsumura, T., Orikasa, N., and Shoji, Y.: Comparisons of Raman Lidar Measurements of Tropospheric Water Vapor Profiles with Radiosondes, Hygrometers on the Meteorological Observation Tower, and GPS at Tsukuba, Japan, J. Atmos. Ocean. Tech., 24, 1407-1423, doi:10.1175/JTECH2056.1, 2007.

Tompkins, A. M.: A Prognostic Parameterization for the Subgrid-Scale Variability of Water Vapor and Clouds in Large-Scale Models and Its Use to Diagnose Cloud Cover., J. Atmos. Sci., 59, 1917-1942, doi:10.1175/15200469(2002)059<1917:APPFTS>2.0.CO;2, 2002.

Turner, D. D. and Goldsmith, J. E. M.: Twenty-Four-Hour Raman Lidar Water Vapor Measurements during the Atmospheric Radiation Measurement Program's 1996 and 1997 Water Vapor Intensive Observation Periods, J. Atmos. Ocean. Tech., 16, 1062-1076, doi:10.1175/15200426(1999)016<1062:TFHRLW>2.0.CO;2, 1999.

Turner D. D., Ferrare R. A., Brasseur L. A. H., Feltz W. F., and Tooman T. P.: Automated Retrievals of Water Vapor and Aerosol Profiles from an Operational Raman Lidar, J. Atmos. Ocean. Tech., 19, 37-50, doi:10.1175/15200426(2002)019<0037:AROWVA>2.0.CO;2, 2002.

Turner, D. D., Lesht, B. M., Clough, S. A., Liljegren, J. C., Revercomb, H. E., and Tobin, D. C.: Dry Bias and Variability in Vaisala RS80-H Radiosondes: The ARM Experience, J. Atmos. Ocean. Tech., 20, 117-132, doi:10.1175/15200426(2003)020<0117:DBAVIV>2.0.CO;2, 2003.

Twomey, S.: Aerosols, clouds and radiation, Atmos. Environ., 25, 2435-2442, doi:10.1016/0960-1686(91)90159-5, 1991.

Wandinger, U.: Raman Lidar, in: Lidar - Range-Resolved Optical Remote Sensing of the Atmosphere, edited by: Weitkamp, C., vol. 102 of Springer Series in Optical Sciences, 241-271, Springer Berlin/Heidelberg, 2005.

Weckwerth, T. M., Parsons, D. B., Koch, S. E., Moore, J. A., Lemone, M. A., Demoz, B. B., Flamant, C., Geerts, B., Wang, J., 
and Feltz, W. F.: An Overview of the International $\mathrm{H}_{2} \mathrm{O}$ Project (IHOP_2002) and Some Preliminary Highlights, B. Am. Meteorol. Soc., 85, 253-277, doi:10.1175/BAMS-85-2-253, 2004.

Westwater, E. R., Crewell, S., Mätzler, C., and Cimini, D.: Principles of surface-based microwave and millimeter wave radiometric remote sensing of the troposphere, Quad. Soc. Ital. Elettromagnetismo, 1, 50-90, 2005.

Whiteman, D. N.: Examination of the traditional Raman lidar technique. II. Evaluating the ratios for water vapor and aerosols, Appl. Opt., 42, 2593-2608, doi:10.1364/AO.42.002593, 2003.

Whiteman, D. N., Melfi, S. H., and Ferrare, R. A.: Raman lidar system for the measurement of water vapor and aerosols in the earth's atmosphere, Appl. Opt., 31, 3068-3082, doi:10.1364/AO.31.003068, 1992.

Whiteman, D. N., Demoz, B., di Girolamo, P., Comer, J., Veselovskii, I., Evans, K., Wang, Z., Cadirola, M., Rush, K., Schwemmer, G., Gentry, B., Melfi, S. H., Mielke, B., Venable, D., and van Hove, T.: Raman Lidar Measurements during the International $\mathrm{H}_{2} \mathrm{O}$ Project. Part I: Instrumentation and Analysis Techniques, J. Atmos. Ocean. Tech., 23, 157-169, doi:10.1175/JTECH1838.1, 2006a.
Whiteman, D. N., Demoz, B., di Girolamo, P., Comer, J., Veselovskii, I., Evans, K., Wang, Z., Sabatino, D., Schwemmer, G., Gentry, B., Lin, R.-F., Behrendt, A., Wulfmeyer, V., Browell, E., Ferrare, R., Ismail, S., and Wang, J.: Raman Lidar Measurements during the International $\mathrm{H}_{2} \mathrm{O}$ Project. Part II: Case Studies, J. Atmos. Ocean. Tech., 23, 170-183, doi:10.1175/JTECH1839.1, 2006b.

Wulfmeyer, V., Behrendt, A., Kottmeier, C., Corsmeier, U., Barthlott, C., Craig, G. C., Hagen, M., Althausen, D., Aoshima, F., Arpagaus, M., Bauer, H.-S., Bennett, L., Blyth, A., Brandau, C., Champollion, C., Crewell, S., Dick, G., di Girolamo, P., Dorninger, M., Dufournet, Y., Eigenmann, R., Engelmann, R., Flamant, C., Foken, T., Gorgas, T., Grzeschik, M., Handwerker, J., Hauck, C., Höller, H., Junkermann, W., Kalthoff, N., Kiemle, C., Klink, S., König, M., Krauss, L., Long, C. N., Madonna, F., Mobbs, S., Neininger, B., Pal, S., Peters, G., Pigeon, G., Richard, E., Rotach, M. W., Russchenberg, H., Schwitalla, T., Smith, V., Steinacker, R., Trentmann, J., Turner, D. D., van Baelen, J., Vogt, S., Volkert, H., Weckwerth, T., Wernli, H., Wieser, A., and Wirth, M.: The Convective and Orographically-induced Precipitation Study (COPS): the scientific strategy, the field phase, and research highlights, Q. J. R. Meteorol. Soc., 137, 3-30, doi:10.1002/qj.752, 2011. 